\title{
On Scientific-Technological Ethics
}

\author{
Lilin Peng \\ Southwestern Institute of Physics, \\ P.O. Box 432, \\ Chengdu, China \\ pllsw@swip.ac.cn
}

\begin{abstract}
Ethics and morality is old and constantly updated topic. In the modern science and technology rapid development situation, study of ethics of science and technology is relatively backward. The times call for advanced and reasonable ethics of science and technology. Basic concepts and characteristics of ethics and morals are distinguished and defined in this paper. Three ethic essences of science-technology are abstracted from scientific-technological generation, application and development. The three-dimension system of basic principles for scientific-technologic ethics is created, as illustrated by the portions given in this paper. The evolution formula of value system is derived, and used for appraising whether the sciencetechnology activity is in all reason. Furthermore it provides the theory base for quantified management. Finally it is pointed out that morality and law should be supplemented each other in the science-technology management.
\end{abstract}

Keywords: science-technology; Ethics; morality; threedimension system; quantified management.

\section{CONCEPTS OF ETHICS AND MORALS}

\section{A. Extremely Important to Understand the Concept}

\section{B. The Misunderstanding}

- Ethics and morality are confused : Ethnics is science of morality and its development law.

If so, it should be called as morals directly.

- Take the words too literally: "lun"__ The rank relationship, "li"_ Jade subtle grain, "lunli (ethics)" harmonious and orderly interpersonal relationship.

However ethical issues discussed at all times and in all countries are far beyond the interpersonal relationship.

\section{The Ideas of Specialists}

- Mr. Yuan-Pei Cai: Ethnics is different from moral books to show people the moral norm. "The purpose is to study the theory....... to induct the highest concept."

- Known as logical positivism German philosopher and scientist pointed out: " Ethics is a branch of science." "It is a knowledge system. Its sole aim is to pursue truth."

D. Definition in This Paper

- Ethics-Basic principle and ideal state with similar essence, abstracted from the related objective existence of people or things, through successive upgrade classification comparison research.

- morality — The norms of behavior from a certain ethical thought by the ruling class or "presided over the Weathering" choice advocate or recognize, most people are willing to accept and agree to abide.

\section{CHARACTERISTICS OF ETHICS AND MORALITY}

A. Both Of Ethics and Morality are Closely Related, but Different

- $\quad$ Ethics emerged earlier than morality. Ethics is an objective law. Evaluation standard of ethics is yes and no.

- Morality is the artificial norm. Evaluation standard of morality is good and bad or good and evil. Morality plays an important role of guidance, supervision and regulation in social life through moral education, public opinion, traditional habits etc.

B. Ethic Characteristics: Objective Being-in-Itself, Abstraction Gradationally, Ideality

- Ethics is the objective law of the universal existence, whether people understand or not, it's always there. There are different ethics on different object of study, for example, social ethics, sciencetechnology ethics, and ecological ethics and so on.

- From contrast of the many people, many things, many causality to understand the ethics. Comparison and abstraction of different levels will obtain the ethics in different levels.

- $\quad$ From lower to higher level abstract results, we will get a higher ideal realm. Objective things are changing, people understanding of ethics with the constant improving and deepening. The future is endless.

C. Moral Characteristics: Artificial Selectivity, Duality of Function, Ideality

Built on the basis of advanced ethics, morality is a light in the heart of people. 


\section{THE ETHICS ESSENCES OF SCIENCE-TECHNOLOGY}

The ethics essences of science-technology are abstracted from the generation, application and development of science-technology (s-t).

A. S-t is Natural laws Revealed and Mastered by Human.

B. S-t is the Elongation of Human Body Organs and the Extension of Organic Function. It is Tools and Methods to Improve the Human Living Conditions

C. S- $t$ is the Crystallization of Wisdom for Realizing Human Ideal

\section{BASIC PRINCIPLE OF SCIENTIFIC-TECHNOLOGICAL ETHICS}

Ethics of science and technology is the basic principle and the ideal state with similar essence that is abstracted from people and things related science and technology. There are three basic ethical principles corresponding to the generation, application and development of sciencetechnology.
A. Originally so - for the True
B. Rightly so — for the Goodness
C. Ideally so - for the Perfectness

The highest ideal state is in harmonic unity and coordinate development with the true, the goodness and the perfectness. The three-dimension system of basic principles for scientific-technologic ethics is created. Figure 1 shows abstracted processes by ordering parameters. There is a relationship of mutual difference, cross each other, complement each other among three order parameters of each system.

\section{INNOVATION AND APPLICATION OF THE EVOLUTION FORMULA OF VALUE SYSTEM}

\section{A. It is Necessary to Appraise Science-Technology Behaviors Quantitatively}

For example, the value system is divided into seven regions as shown in Figure 2 (medial).

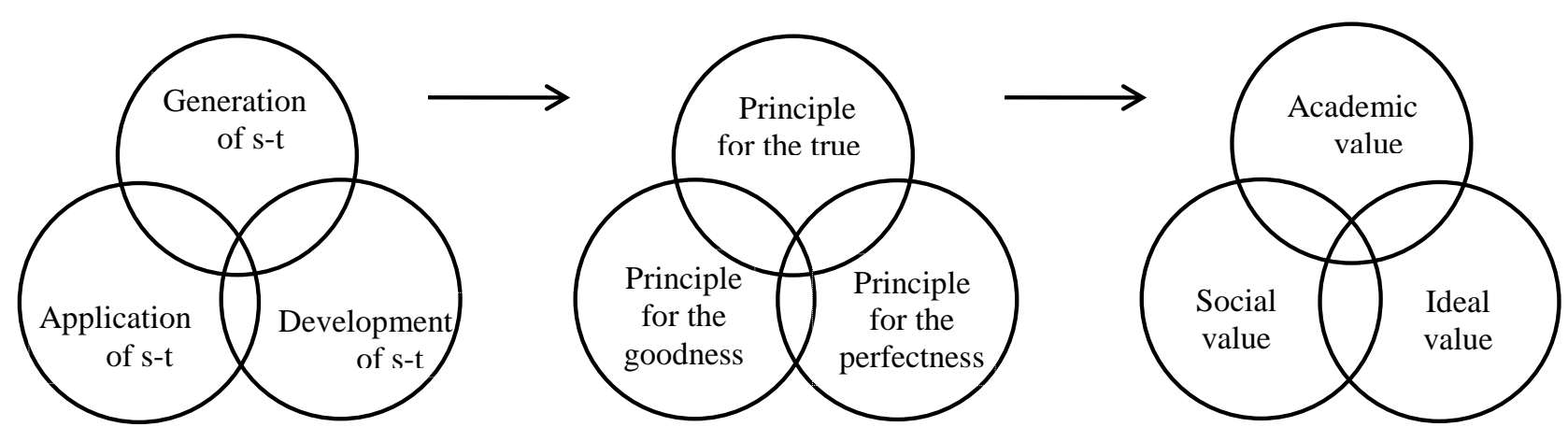

Figure 1. Diagram of basic principle system of science-technology ethics
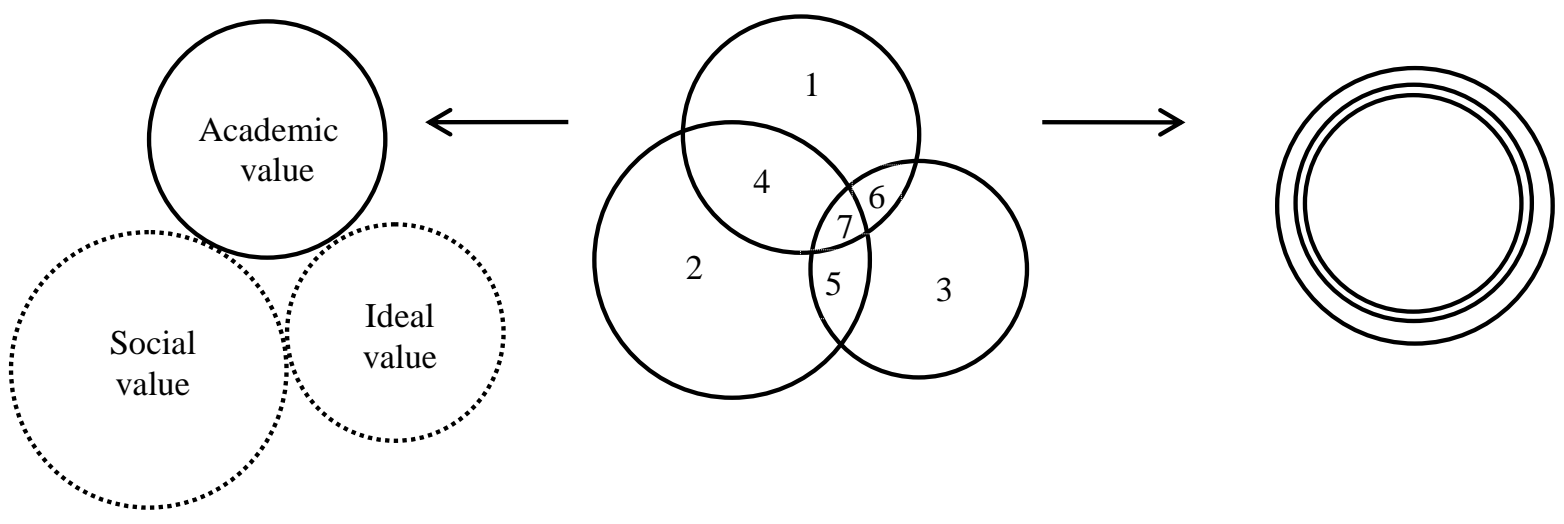

Figure 2. Diagram of value system and its limit states 
- $\quad$ 1. The region of academic value;

2. The region of social value;

3 . The region of ideal value;

4. The combined region of academic value and social value;

5. The combined region of social value and ideal value;

6. The combined region of academic value and ideal value;

7. The combined region of academic value, social value and ideal value.

- The region 7 is the core region of the system. The bigger, the better.

- Left: the limit case without combination of three ordering parameters.

- $\quad$ Right: the limit case with complete combination of three ordering parameters.

\section{B. Create the Evolution Formula of Value System}

- Defined that the total value of the sciencetechnology activities is $V$, academic value, social value and ideal value are $V_{R_{1}}, V_{R_{2}}, V_{R_{3}}$ respectively, the evolution formula of value system is

$$
\begin{gathered}
V=V_{R_{1}}+\mathrm{r}_{12}\left(V_{R_{1}}+V_{R_{2}}\right)+\mathrm{r}_{23}\left(V_{R_{2}}+V_{R_{3}}\right) \\
+\mathrm{r}_{13}\left(V_{R_{1}}+V_{R_{3}}\right)+\mathrm{r}_{123}\left(V_{R_{1}}+V_{R_{2}}+V_{R_{3}}\right)
\end{gathered}
$$

Where $r_{12}, r_{23}, r_{13}, r_{123}$ are combination coefficients.

- Before science discovery and technology invention are not developed and applied to practice, all combination coefficients are equal to zero. The total value is equal to $V_{R_{1}}$. There is only academic value. That is corresponded to the system state of left side in Figure 2.

- If all combination coefficients are equal to 1, i.e. $100 \%$ (corresponding to the system state of right side in Figure 2), the total value is

$$
V=V_{R_{1}}+3\left(V_{R_{1}}+V_{R_{2}}+V_{R_{3}}\right)
$$

- Weight: $V_{R_{2}}>V_{R_{1}}>V_{R_{3}}$, i.e. big circle, middle circle, and small circle as shown in Figure 2. It indicates that the application of science and technology to sociality is the urgent need, innovation of science and technology is the premise, and correct and perfect application is our pursuit of the ultimate goal.

\section{Application}

- Science and technology activities in most cases are in Figure 2 intermediate states, but there is a difference in degree. For example, the town in upstream takes off deficient to become rich by science-technology $\left(r_{12}>0\right)$, but do not pay attention to environmental protection $\left(\mathrm{r}_{13}=0, \mathrm{r}_{123}=\right.$ $0)$. Pollution is serious, affecting the downstream $\left(r_{23}<0\right)$. The total value decreases, even the loss outweighs the gain. The formula (1) becomes

$$
V=V_{R_{1}}+\mathrm{r}_{12}\left(V_{R_{1}}+V_{R_{2}}\right)-\left|\mathrm{r}_{23}\right|\left(V_{R_{2}}+V_{R_{3}}\right)
$$

Using advanced technology to process the waste gas, waste water, waste residue, the ecological environment is improved later. The total value expression recoveries formula (1). If changing waste to treasure by using high technology, the total value will increase greatly. Therefore three order parameters of the each system and its combination coefficients are the quantization parameters indicating system ordering. They can characterize the system from disorderly to orderly evolution, is a measure of the overall rational effect, and can reverse control subsystem or component behavior, promote the evolution of the whole system. In the human activities of science and technology, system theory plays a role of constraint and regulate people's behavior that is rationalization and idealization.

- $\quad$ Quantified management

Assuming academic value $V_{R_{1}}=1,2 、 3 、 4 、 5$ grade (or mark), social value $V_{R_{2}}=1.2 、 2.4 、 3.6 、 4.8 、 6.0$ grade (or mark), ideal value $V_{R_{3}}=0.8 、 1.6 、 2.4 、 3.2 、 4.0$ grade (or mark), and $\mathrm{r}_{12}=-0.2 、 0 、 0.2 、 0.4 、 0.6, \mathrm{r}_{13}=$ $0 、 0.2 、 0.4 、 0.6 、 0.8, \mathrm{r}_{23}=-0.2 、 0 、 0.2 、 0.4 、 0.6$; $\mathrm{r}_{123}=0 、 0.2 、 0.4 、 0.6 、 0.8$, correspondent practice cases are attached. And then, quantified management is able to operate through test, revisal and complementary.

\section{MORALITY AND LAW SUPPLEMENTED EACH OTHER}

A. Active And Discreet, Make Best Use of the Advantages and Bypass the Disadvantages

Science and technology academic value, social value and ideal value orientation, in most cases is complementary, but sometimes may conflict with each other, with a potential threat or danger to society or nature. For example:

- Damage to the ecological environment by industrial science-technology

- Nuclear weapon deterrent to destruct of human civilization

- The health risks of medical research subjects

- Doubts about side effects of genetically modified food on the human body

- Cloning technology triggered a chain reaction etc.

B. Science and Technology Itself has not the Natural Instinct to Choose the Good and Evil. It Needs the Guide of Human reason, to Take a Positive and Prudent Attitude 
- Science-technology of every new major breakthrough, will put forward new ethical and moral issues, and challenge to the traditional ethics. We can't restrict science-technology development by using the old ethics, should break through the constraint of antiquated ethical norms, and reveal new ethics of science and technology in accordance with the objective law of development of things.

- Science-technology experts to research consequences should have strong sense of responsibility. There is information regulation for applicable conditions or negative effect of research results, duty of warning and prevention for environmental pollution.

- The lower bound of morality is the law. When the moral strength is not enough to keep oneself or others under control, we will have to rely on the majesty of the law, legislation to ban.

For example, although the voice of environmental protection in the society is very high, from the point of view of narrow utilitarianism principle to reduce cost, improve economic efficiency, enterprise legal person often take the " first of all is rich", "pollution first, treatment later", or even "I pollution, governance treatment later " approach. So, the government departments will advance in the approval of the construction project, according to the environmental protection law obliges companies. In the planning stage of the construction, to the waste treatment system as the infrastructure components, will be permitted to build. After the completion it is necessary to inspect and supervise if meets the environmental protection index or not, to take sanctions against illegal activities according to law.

\section{Law is Focus on Punishing the Evil, Morality Emphasis on Goodness}

The conduct norm and moral criterion followed by the experts engaged in scientific and technological activities, participants of various types, intervenient etc, is called as moral norm of science-technology. A most of Scientifictechnological misconducts does not belong to the jurisdiction of the law, it depends on self-discipline and public opinion condemns for overcome, prevent, purification.

\section{THE CALL OF THE TIMES}

Ethics and morality is old and constantly updated topic. In the modern science and technology rapid development situation, study of ethics of science and technology is relatively backward. The times call for advanced and reasonable ethics of science and technology that will be revealed and unremitting pursuit. Ethics is the foundation to build morality. Morality is the embodiment of advocated ethics. And the law is the most basic moral criterions. Its execution is ensured by the state power. The establishment of moral norms must be based on correct and advanced ethical thoughts, to improve the rational consciousness and moral level of the whole nation, and to correct the party atmosphere. Timely formulate corresponding law as the backing, to enforce the basic moral criterion. Strive to make scientific-technological invention and application is less harmful for human benefit, is the social development to be perfect and human development tends to mature perfect performance. The strong vitality of the science-technology ethics advanced and reasonable, will be more and more people know, choose and accept, and will be positive guidance and adjustment function in the world sciencetechnology development tide.

\section{REFERENCES}

[1] Li-Lin Peng, "Scientific-technological ethics ", Chinese Sscience and Technology Forum, 2001, No. 5.

[2] Li-Lin Peng, "Supplement to the evaluation formula of value system of science-technology ethics", Chinese Science and Technology Forum, 2002, No. 5.

[3] Jan-Xin Guo, Wen-Bing Yang, "The new ethics course", Economic Management Press, 1999, p2.

[4] Bao-Lu Gan, "An introduction to ethics" , Higher Education Press, 1994, p2.

[5] Yuan-Pei Cai, "Chinese ethics history", The Commercial Press, 1998 Ed., p1.

[6] M. Schlick, "The problem on ethics", The Commercial Press, 1997, p11.

[7] Shui-Fa Jiang, Li-Ming Liang, Qian-Fang Shen, "Introduction to spiritual civilization in science-technology circles", Economic Management Press, 2000, p25.

[8] Shao-Feng Chen, "Chinese ethics history", Beijing University Press, 1997, 12.

[9] Hua-Xia Zhang, "Modern science and ethics world", Hunan EducationPress, 1999,p130. 